\title{
THIAMINE IMPROVES LEAD-INDUCED NEUROTOXICITY IN RATS: BEHAVIORAL, BIOCHEMICAL AND STRUCTURAL ASSESSMENT
}

\author{
OSAMA S. EL OKLE ${ }^{1}$; HOSSAM G. TOHAMY ${ }^{2}$ and RASHED R. RASHED ${ }^{3}$ \\ ${ }^{1}$ Department of Forensic Medicine and Toxicology, Faculty of Veterinary Medicine, Alexandria University, Egypt. \\ ${ }^{2}$ Department of Pathology, Faculty of Veterinary Medicine, Alexandria University, Egypt. \\ ${ }^{3}$ Department of Animal Husbandry and Animal Wealth Development. Faculty of Veterinary Medicine Alexandria \\ University, Egypt.
}

Received: 24 March 2016; Accepted: 6 April 2016

\begin{abstract}
This study was designed to investigate neuro-behavioral, neuro-biochemical and neuro-morphological alterations induced by sub-acute toxicity of lead $(\mathrm{Pb})$ in male Wistar rats as well as the assessment of the neuroprotective effect of thiamine hydrochloride against $\mathrm{Pb}$-induced behavioral, biochemical and morphological neuroalterations. For this purpose 24 male Wistar rats were randomly divided into 4 groups $(n=6)$. Rats in the $1^{\text {st }}$ group were treated with lead acetate orally at dose of $100 \mathrm{mg} / \mathrm{kg} \mathrm{b}$.wt. Animals in $2^{\text {nd }}$ group were received leaded water orally $+100 \mathrm{mg} / \mathrm{kg}$ thiamine hydrochloride intraperitoneally. $3^{\text {rd }}$ group were treated only with thiamine hydrochloride. $4^{\text {th }}$ group was served as the control animals. Animals were exposed to treatments once daily for 7 consecutive days. Behavioral alterations were assessed by applying neurological tests as elevated plus-maze and Morris water maze. The main neurotransmission systems as cholinergic, adrenergic, serotonergic and GAB Aergic were evaluated in brain tissue homogenate. Morphological alterations was assessed histopathologically. Results revealed that, $\mathrm{Pb}$ exposure caused spatial learning and memory impairment, as well as a significant increase in the content of acetylcholine, serotonin and norepinephrine while the activity of acetylcholinesterase and GABA content showed a significant decrease. Hemorrhage in brain, mild perivascular edema and perivascular cuffing were the main pb-induced morphological alterations. Simultaneous administration of thiamine markedly ameliorated $\mathrm{Pb}$-induced neurotoxicity which was indicated by comparatively better behavioral performance, alleviation of the neurotransmitters disturbances and decreased the severity of histopathological lesions. In conclusion, thiamine has been found to be extremely significant in the fighting of $\mathrm{Pb}$-induced neuro-manifestations.
\end{abstract}

Key words: Lead, Neurotoxicity, Neurotransmitters, Histopathology, Thiamine.

\section{INTRODUCTION}

Lead $(\mathrm{Pb})$ is a wide spread toxic metal found in the environment and considered a potential danger for human and animal health. It is known that $\mathrm{Pb}$ has detrimental effects on the central and peripheral nervous systems causing behavioral abnormalities, learning impairment, decreased hearing, and impaired cognitive functions in humans and laboratory animals (Bijoor et al., 2012). Therefore, among all livestock, clinical signs of $\mathrm{Pb}$ toxicity usually related to the central nervous system and digestive system (Krametter-Froetscher et al., 2007). Mechanisms of

Corresponding author: Dr. OSAMA S. EL OKLE

E-mail address: Oklevetmed@yahoo.com

Present address: Department of Forensic Medicine and

Toxicology, Faculty of Veterinary Medicine, Alexandria University, Edfina, Rasheed, Egypt.
$\mathrm{Pb}$ encephalopathy include: damage of the endothelial cell of the blood-brain barrier leading to entry of $\mathrm{Pb}$ into the brain, followed by morphologic and biochemical effects such as impairment of timed programming of cell-cell connections, interferes with neurotransmitter function and disrupts calcium metabolism which is a critical component of numerous biochemical and metabolic functions in the brain (Goyer and Clarkson, 2001). Moreover there is a correlation between $\mathrm{Pb}$ neurotoxicity and nitric oxide synthesis in central nervous system via the impairment of nitric oxide synthase (NOS) activity in brain (Nava-Ruiz et al., 2012). Also, N-methyl-Daspartate (NMDA) receptor (excitatory amino acid receptor play an important role in learning and memorizing) in the hippocampus region is an important target of $\mathrm{Pb}$ during the developmental period (Zhu et al., 2005).

Previous studies have shown beneficial effects of thiamine hydrochloride on $\mathrm{Pb}$ toxicity as it reduced 
the deposition of $\mathrm{Pb}$ in central nervous system of experimentally poisoned calves or in blood, kidney and bone during both simultaneous and post-exposure $\mathrm{Pb}$ treatment in rats (Radostits et al., 2000; Reddy et al., 2010). Also thiamine has the ability to decrease $\mathrm{Pb}$-induced lipid peroxidation in rat hepatic and renal tissues (Senapati et al., 2000).

Although the investigations considering the prevention or treatment of $\mathrm{Pb}$ toxicity by thiamine are fairly well defined, the exact role of thiamine in antagonizing $\mathrm{Pb}$-induced neurotoxicity has not been clearly elucidated until now.

In this regard, the first aim of the present study was to investigate the effect of $\mathrm{Pb}$ on the content of neurotransmitters in rat brain homogenate, along with changes seen in behavior and morphological structure. The second objective of this experiment was to evaluate the protective effect of thiamine against lead-induced neuro-alterations which guided behaviorally, biochemically and histopathologically.

\section{MATERIALS AND METHODS}

\section{Animals, chemicals and experimental design:}

Twenty four male Wistar rats weighing $200 \pm 10 \mathrm{~g}$ were used in the present study. Animals were obtained from the laboratory animal center in the Department of Forensic Medicine and Toxicology, Faculty of Veterinary Medicine, Alexandria University, Egypt and maintained under standard conditions of temperature $\left(28 \pm 2^{\circ} \mathrm{C}\right)$ with a 12-h dark/light cycles. Rats were provided with commercial rodent feeds and water was supplied $\mathrm{ad}$ lib.

After 7 days acclimatization period, rats were randomly assigned into 4 groups $(n=6)$. A sub acute toxicity study of seven days was conducted. Rats in $1^{\text {st }}$ group received $100 \mathrm{mg} / \mathrm{kg}$ b.wt lead acetate orally using stomach tube once a day + intraperitoneal injection of normal saline. Animals in $2^{\text {nd }}$ group were given leaded water as in $1^{\text {st }}$ group + intraperitoneal injection of $100 \mathrm{mg} / \mathrm{kg}$ b.wt thiamine hydrochloride. Rats in $3^{\text {rd }}$ group were treated with $100 \mathrm{mg} / \mathrm{kg}$ b.wt thiamine hydrochloride intraperitoneally + normal saline orally. In $4^{\text {th }}$ Group, rats served as negative control and received normal saline orally and intraperitoneally.

Lead acetate $[(\mathrm{CH} 3 \quad \mathrm{COO}) 2 \mathrm{~Pb} .3 \mathrm{H} 2 \mathrm{O}]$ with a laboratory reagent grade was obtained from El Nasr Pharmaceutical Chemicals Co, Egypt, while, thiamine hydrochloride from Lobachemie Chemicals Co, Alexandria, Egypt.

\section{Neurobehavioral assessment}

After 7 consecutive days of exposure, animals were tested for behavioral changes as the following:
Morris water maze (MWM). The memory and spatial learning ability were investigated according to method of Morris, (1984). Animals were tested in a circular pool of $190 \mathrm{~cm}$ in diameter and $45 \mathrm{~cm}$ in height. The pool was filled with opaque water using powdered milk. The pool temperature was maintained at $26 \pm 1{ }^{\circ} \mathrm{C}$. Two small hidden plastic platforms were located $1-2 \mathrm{~cm}$ under water's surface. The rat is placed on a start platform. The rat swims around until it finds the other platform to stand on. External cues, such as patterns or the standing researcher, are placed around the pool in the same spot every time to help the rat learn where the end platform is. The time a rat took to find a hidden platform, termed latency and expressed by seconds, was recorded.

Elevated plus-maze test (EPM). Anxiety-related behavior is measured using EPM test on the basis described by Kulkami and Sharma (1991); Mulder and Pritchett (2004). Testing session consists of putting the rats individually in the center of the apparatus to start. The numbers of entries into each portion of the EPM (open and closed arms) are scored in addition to the total time spent in each portion. The maze is cleaned with $70 \%$ ethanol after every trial. The total test time is 3 minutes for each animal.

\section{Neurobiochemical assessment}

After rapid decapitation, brain was dissected out and carefully hemi-sectioned on ice. Left hemisphere of brain was placed in ice and then quickly stored in deepfreeze under $-80^{\circ} \mathrm{C}$ until the analysis of neurotransmitters. Content of neurotransmitters were determined in the whole left brain hemisphere homogenate using specific commercial kits. Acetylcholine (ACh) was determined by acetylcholine assay Kit (colorimetric) from ABNOVA; Cholinesterase (AChE) by cholinesterase determination kit from Quimica clinica aplicada S.A. Spain; 5-HT (Serotonin) by Serotonin ELISA kit from ALPCO Diagnostics; Gamma-aminobutyric acid (GABA) by Rat GABA ELISA Kit from ABNOVA and noradrenaline by Rat Noradrenaline ELISA Kit from CUSABIO.

\section{Histopathological examination}

The right brain hemisphere and spinal cord were quickly removed and immersed in $10 \%$ neutral buffered formalin solution for tissue fixation. Afterwards it was rinsed with distilled water, dehydrated in graded alcohol, cleared in xylene and embedded in paraffin. Finally from the prepared paraffin blocks, 3-5 $\mu \mathrm{m}$ thick sections were obtained and stained with hematoxylin and eosin (HE) for light microscopic examination (Culling, 1983).

\section{Statistical analysis}

Data were expressed as mean \pm SEM. The data obtained was analyzed using the computerized program CoStat by one way ANOVA. The $P$ values 
of $<0.05$ were considered to identify statistically significant levels.

\section{RESULTS}

\section{Neurobehavioral alterations}

$M W M$ test: Rats in control group, thiamine treated group and $\mathrm{Pb}+$ thiamine treated group solve water maze in a little time $6.75 \pm 3.20,5.50 \pm 1.85$ and $8.75 \pm 1.25 \mathrm{sec}$, respectively, while the longer time taken by $\mathrm{Pb}$ only exposed group $(25.00 \pm 2.86 \mathrm{Sec})$ (Figure 1)

EPM test: As shown in Table 1, Pb-treated rats spent a long time in the closed arm and short time in the open arm as compared with control and thiamine treated groups. Rats treated by $\mathrm{Pb}+$ thiamine spent a relatively longer period in open arm and a shorter period in closed arm when compared with $\mathrm{Pb}$ only exposed animals. The longest period observed in open arm and the shortest period in closed arm was related to thiamine- treated rats. Moreover, data for the frequencies of entries into each portion of the EPM revealed that total number of entries into open arm was the lowest in $\mathrm{Pb}$ exposed rats followed by $\mathrm{Pb}$ +thiamine group then control group, while the highest frequencies observed in animals received only thiamine. On the contrary, frequency of entries into closed arm was highest in $\mathrm{Pb}$ received group followed by $\mathrm{Pb}+$ thiamine, control and thiamine treated groups, respectively.

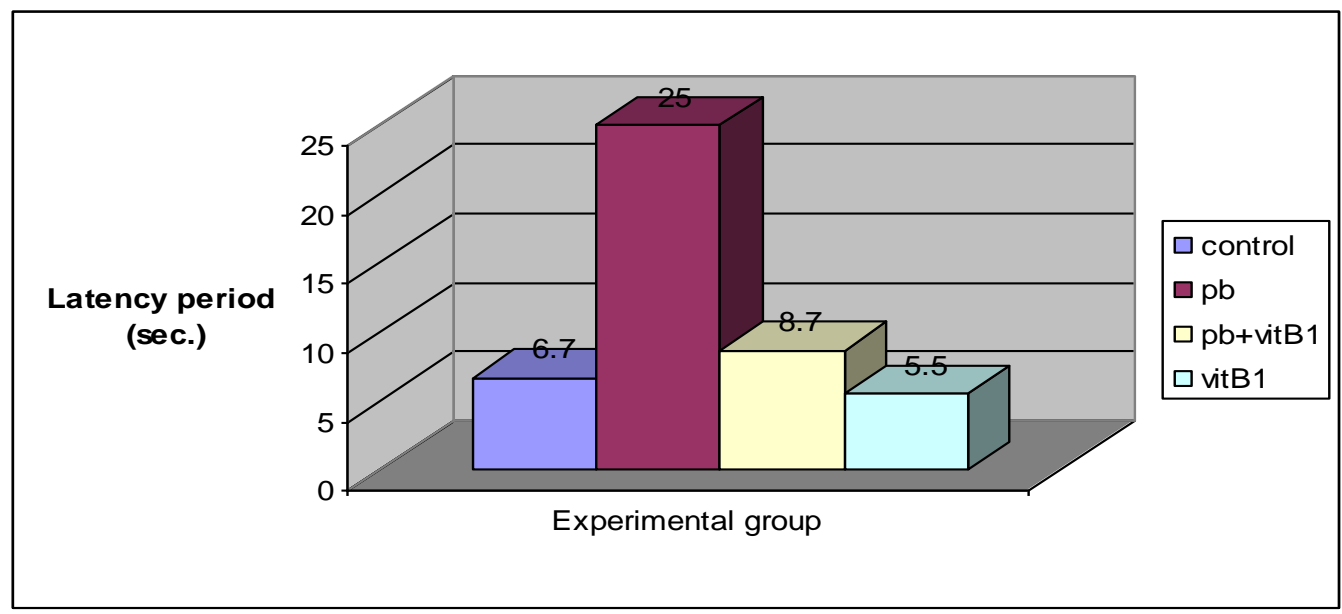

Fig.1: Effect of $\mathrm{Pb}$ with or without thiamine on learning ability of rat in water maze test

Table 1: Effect of $\mathrm{Pb}$ with or without thiamine on behavioral performance of rats during elevated plus maze test

\begin{tabular}{lcccc}
\hline & Control & Pb & thiamine & Pb+thiamine \\
\hline LPOA (sec.) & $27.50 \pm 10.05$ & $10.00 \pm 7.07^{*}$ & $62.25 \pm 37.20$ & $20.25 \pm 7.05^{* *}$ \\
\hline LPCA (sec.) & $152.50 \pm 10.05$ & $170.00 \pm 7.07^{*}$ & $117.75 \pm 37.20$ & $161 \pm 7.05^{* *}$ \\
\hline FOA (sec.) & $1.50 \pm 0.50$ & $1.25 \pm 0.95$ & $3.50 \pm 0.50$ & $1.40 \pm 0.50$ \\
\hline FCA (sec.) & $2.20 \pm 0.50$ & $2.55 \pm 0.95$ & $2.00 \pm 1.15$ & $2.40 \pm 1.15$ \\
\hline
\end{tabular}

Data are presented as Mean \pm SEM

LPOA: latency period in open arm; LPCA: latency period in closed arm; FOA: frequency of entry in open arm; FCA: frequency of entry in closed arm. $* \mathrm{P}<0.05$ compared between pb exposure group and untreated control group. ${ }^{* *} \mathrm{P}<0.05$ compared between $\mathrm{pb}$ exposure group and $\mathrm{pb}+$ thiamine treated group

\section{Neurobiochemical alterations}

Table 2 summarizes the changes in the content of neurotransmitters after pb exposure with or without the treatment with thiamine. Results showed that the concentration of acetylcholine (ACh) was markedly increased in the whole brain tissue of $\mathrm{Pb}$-treated rat as compared with the untreated controls $(P<0.05)$. However, the co-administration of thiamine with $\mathrm{Pb}$ resulted in a markedly improvement in the levels of ACh $(P<0.05)$ toward control level. The increased concentration of ACh was coupled with decreased activity of acetylcholine esterase (AChE) $(P<0.05)$. Interestingly, the treatment with thiamine relatively restore the activity of $\mathrm{AChE}$ in $\mathrm{Pb}$-treated rats $(P<0.05)$. There was no significant difference in the brain concentration of $\mathrm{ACh}$ or the activity $\mathrm{AChE}$ 
between the control group and thiamine alone treated group.

Considering levels of serotonin $(5-\mathrm{HT})$ and norepinephrine (NE), our results showed that brain of rats exposed to $\mathrm{Pb}$ exhibited a significant increase in the 5-HT and NE content when compared with the control group $(P<0.05)$. On the other hand, $\mathrm{Pb}$ treatment markedly decreased the concentration of GABA in comparing with either control and thiamine only treated group $(P<0.05)$. However, the treatment by thiamine significantly decreased levels of both 5HT and NE $(P<0.05)$ and restored GABA content of brain in $\mathrm{Pb}$ treated rats when compared with $\mathrm{Pb}$ only exposed rats (Table 2).

Table 2: Neurotransmitters content in brain of rats exposed to $\mathrm{Pb}$ with or without thiamine

\begin{tabular}{lcccc}
\hline & Control & Pb & Thiamine & Pb+thiamine \\
\hline ACh $(\mu$ mol/mg protein) & $94.7 \pm 9.39$ & $112.0 \pm 8.96^{*}$ & $95.0 \pm 4.36$ & $98.5 \pm 5.32^{* *}$ \\
\hline AChE(U/mg protein) & $152.5 \pm 17.04$ & $103.7 \pm 3.06^{*}$ & $140.0 \pm 5.01$ & $127.5 \pm 7.81^{* *}$ \\
\hline 5-HT(ng/g tissue) & $253.5 \pm 4.94$ & $531.0 \pm 20.10^{*}$ & $262.0 \pm 30.49$ & $305.5 \pm 8.96^{* *}$ \\
\hline GABA (ng/g tissue) & $1055.2 \pm 37.3$ & $867.5 \pm 30.8^{*}$ & $1120.7 \pm 1.7$ & $967.5 \pm 31.6$ \\
\hline NE (ng/g tissue) & $89.0 \pm 1.82$ & $213.5 \pm 2.66^{*}$ & $74.5 \pm 1.04$ & $92.0 \pm 2.10^{* *}$ \\
\hline
\end{tabular}

Data are presented as Mean \pm SEM

$* \mathrm{P}<0.05$ compared between $\mathrm{pb}$ exposure group and untreated control group

$* * \mathrm{P}<0.05$ compared between $\mathrm{pb}$ exposure group and $\mathrm{pb}+$ thiamine treated group

\section{Histopathological lesions}

Histopathological findings of brain and spinal cord were evaluated under light microscopy. The incidence and severities of detected lesions in selected organs are summarized in (Table 3 ).

Brain of rats received $\mathrm{Pb}$ showed extravasation of erythrocytes from the blood vessels in cerebrum gray matter and meninges (Figs.2a\&b), as well as congestion of choroids plexus vasculature (Fig.2c). Moreover, the perivascular cuffing where the mononuclear inflammatory cells infiltration in Virchow-Robin spaces was also noticed (Fig.2d). The degenerated neurons undergo central chromatolysis where Nissl granules disappeared from the central region of the cell body, leaving this zone with a smooth ground-glass appearance (Fig.2e). Perineuronal satellitosis in which the small degenerated neurons were surrounded by microglia cells which invade and engulf the degenerated neurons in process called neurophagia (Fig. 2f) and gliosis (Fig. 2g) were observed. The spinal cord of intoxicated rat exhibited perivascular cuffing and hemorrhages (Fig.2h). The encountered microscopic lesions of brain of rats co-treated by $\mathrm{Pb}+$ thiamine were hemorrhage (Fig3a) and mild gliosis (Fig.3b). Thiamine-supplemented rats exhibited normal cerebellum, cerebrum and spinal cord histology.

Table 3: Incidence and severity of histopathological lesions in brain and spinal cord of $\mathrm{Pb}$ treated rats and $\mathrm{Pb}+$ thiamine treated rats:

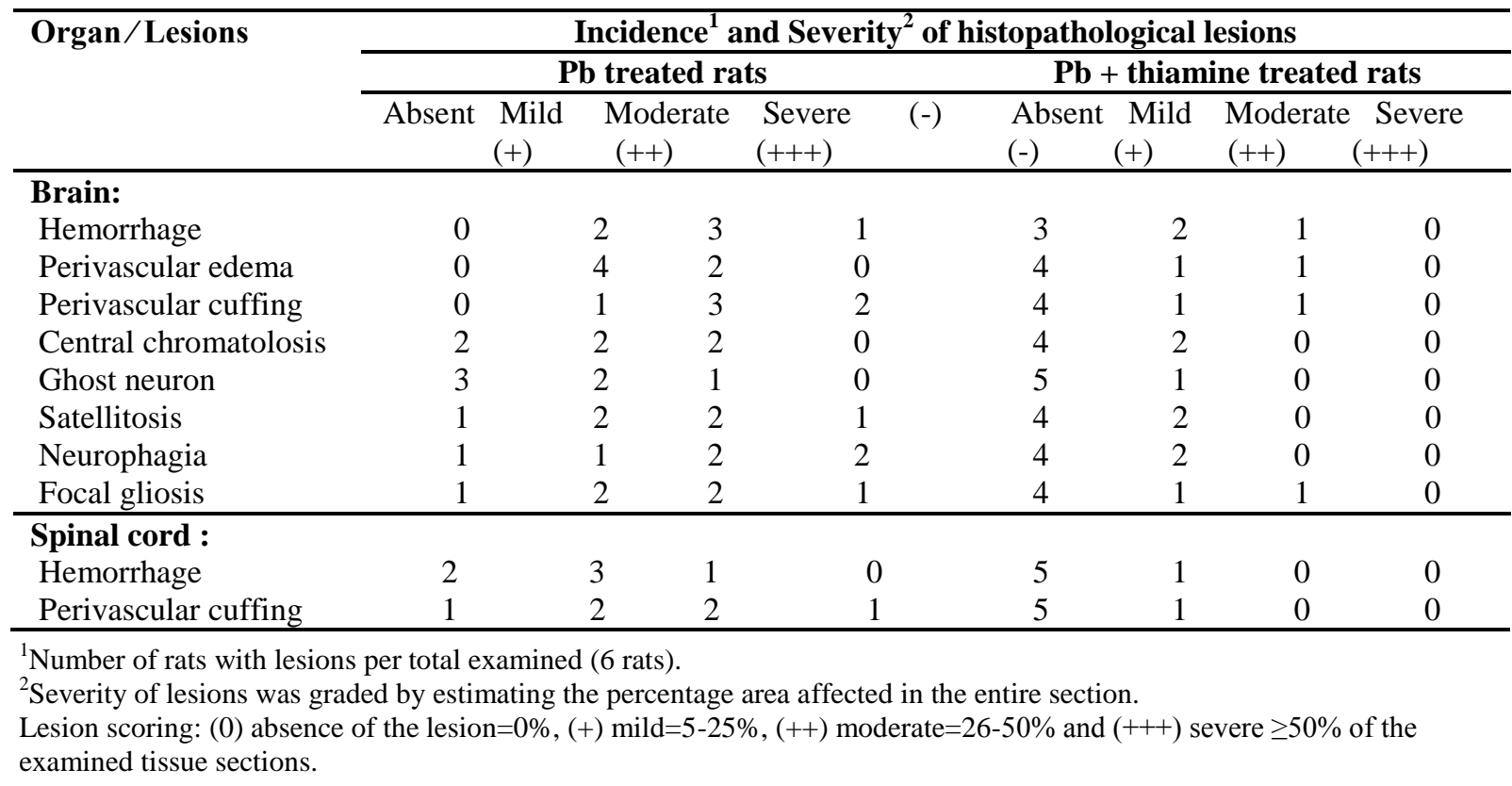



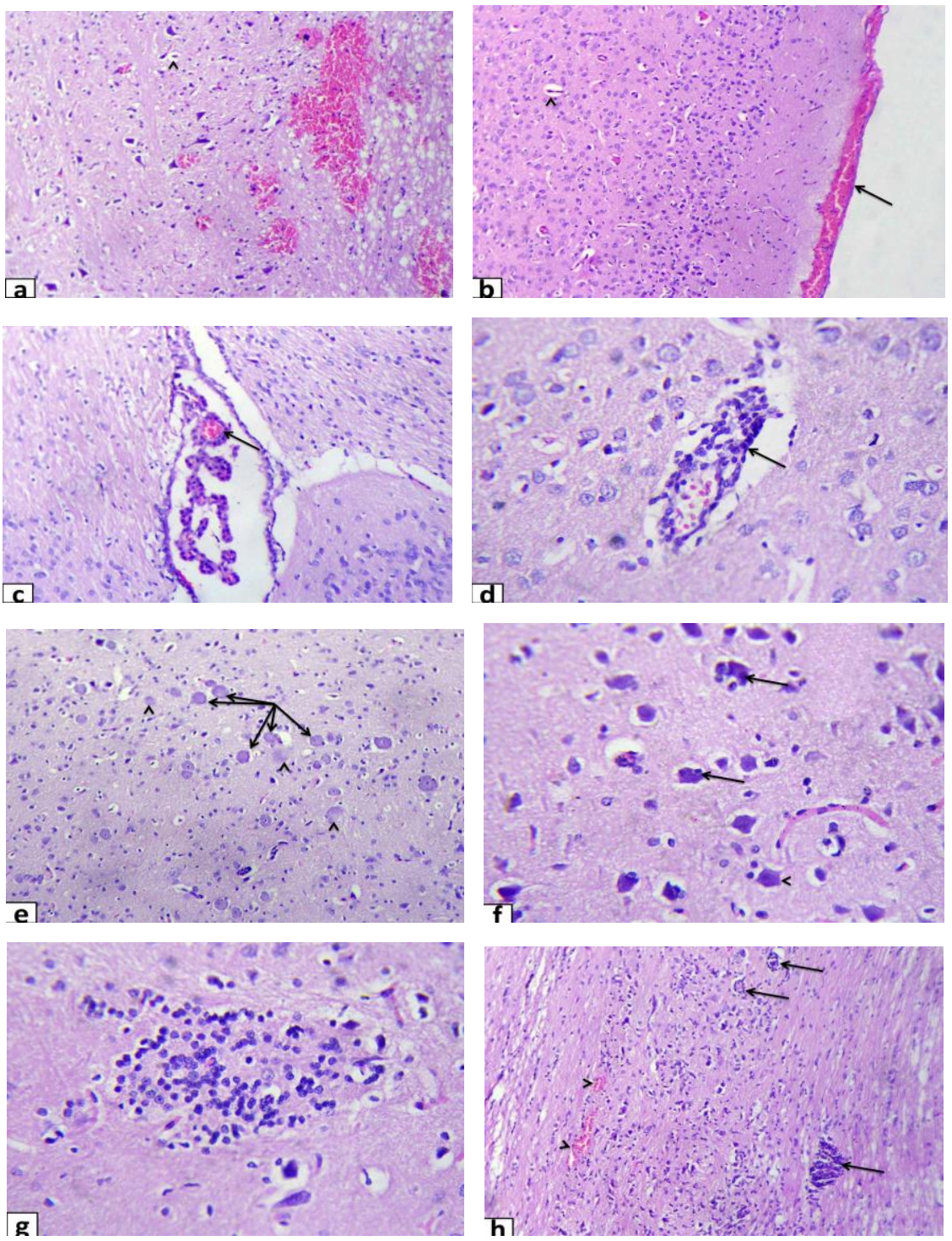

Figure (2): Photomicrograph of brain and spinal cord of rat recieved $100 \mathrm{mg} / \mathrm{kg} \mathrm{Pb}$ orally and stained by HE. (a \&b) Hemorrage in cerebrum gray matter and meninges (arrow) and mild perivascular edema (arrow heads X160). (c) Congestion in the vasculature of choroids plexus (arrow X250). (d) Congestion of blood vessels and infiltration of mononuclar cells in Virchow-Robin spaces (arrow X250). (e) Central chromatolysis of some neurons (arrows) and nearly complete absence of others (ghost cells) (arrowheads X 160). (f) Satellitosis around degenerated neurons (arrows head) and neuronophagia (arrow X 250) (g) Focal gliosis due to proliferation of microglial cells and astrocytes (X 250). (h) The spinal cord showed perivascular cuffing where the infilamatory cell infilteration around blood vessels (arrows) and mild hemorrage (arrow heads X160).
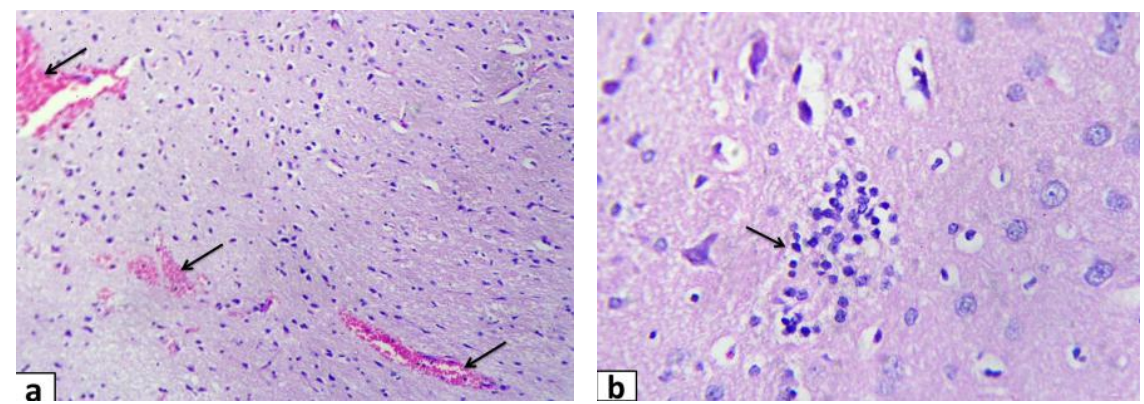

Figure (3): Photomicrograph of brain of rat recieved $100 \mathrm{mg} / \mathrm{kg} \mathrm{Pb}$ orally + intraperitoneal injection of 100 $\mathrm{mg} / \mathrm{kg}$ b.wt thiamine and stained by HE. (a) extravasation of erythrocytes from the blood vessels (arrows). (b ) focal gliosis (arrow) 


\section{DISCUSSION}

Lead $(\mathrm{Pb})$ ions are known to be toxic to the nervous system of man and animals. Both acute and chronic exposures to lead resulted in behavioral and neurological symptoms as vertigo, insomnia, restlessness and irritability and major manifestations such as convulsions and coma (Struzynska and Rafalowska, 1994). Thiamine hydrochloride showed many beneficial effects on $\mathrm{Pb}$ toxicity as it reduced the deposition of $\mathrm{Pb}$ in central nervous system of calves or in blood, kidney and bone during both simultaneous and post-exposure $\mathrm{Pb}$ treatment in rats (Radostits et al., 2000 and Reddy et al., 2010). Also thiamine has the ability to decrease $\mathrm{Pb}$-induced lipid peroxidation in rat hepatic and renal tissues (Senapati et al., 2000).

The present experiment was undertaken to investigate the sub-acute neurotoxic consequences of $\mathrm{Pb}$ exposure on behavior, neurotransmitters and neuromorphology, as well as the evaluation of neuroprotective effect of thiamine hydrochloride against $\mathrm{Pb}$-induced neuro-alterations. Exposure to $\mathrm{Pb}$ is associated with neurobehavioral and psychological alterations, including learning and memory impairment (Phyu and Tangpong, 2014). In this study, Pb-treated rats also exhibited memory loss and deficit in spatial learning ability, as data obtained by using the MWM test which showed longer latency period to find hidden platform during forced swimming than did control rats. Our results are in consistent with previously reported findings (Kuhlmann et al., 1997; Phyu and Tangpong, 2013; Mansouri et al., 2013). The second behavioral test used in our experiment is EPM test. This assay was actually developed to investigate anxiety-related behavior. Generally, test depends on the preference between a safe and comfortable environment (represented as closed arms) and a risky environment (represented as elevated open arms). The more anxious animals are, the less likely they will be to explore a risky environment. It was established that $\mathrm{Pb}$ exposure may possibly induce increased anxiety as a consequence of changes in neuronal 5-HT content in the dorsal raphe nucleus as assessed by Sansar et al. (2012). Obtained data in our experiment suggested that $\mathrm{Pb}$ able to increase anxiety in rats as indicated by spent a long time in closed arm and this was associated with increase 5-HT content in brain as discussed later. The co-administration of thiamine with $\mathrm{Pb}$ ameliorates behavioral changes in comparing with $\mathrm{Pb}$ treated rats. This improvement was represented by solving of water maze in a little time and spending a relatively longer period in open arm during EPM test.

In $\mathrm{Pb}$ neurotoxicology an important issue relates to the interference with chemical neurotransmission. It has been hypothesized that $\mathrm{Pb}^{2+}$ and $\mathrm{Ca}^{2+}$ may competitively interact at the sites involved in the release of neurotransmitters, resulting in the inhibition of Ca-dependent stimulus-coupled release. Some evidence for this hypothesis has been found in studies investigated effect of $\mathrm{Pb}$ on cholinergic, dopamenergic and serotoninergic systems (Sidhu and Nehru, 2003 and Sansar et al., 2012).

$\mathrm{AChE}$ is a serine protease that hydrolyzes the neurotransmitter ACh to be acetyl CoA and choline. $\mathrm{AChE}$ is found mainly at neuromuscular junctions and cholinergic brain synapses. It was investigated that $\mathrm{Pb}$ exposure can decrease the activity of $\mathrm{AChE}$ coupled with increased $\mathrm{ACh}$ in different brain regions (Sidhu and Nehru, 2003; Mansouri et al., 2013; Phyu and Tangpong, 2013). Pb may have high affinity with free $\mathrm{SH}$ group of this enzymes proteins and its binding can alter their function (Phyu and Tangpong, 2013). This may be the reason for the observed inhibition of AChE activity and the subsequent increase in ACh content in our study. Intraperitoneal injection of thiamine concurrently with $\mathrm{Pb}$, relatively, able to restore the activity of AChE toward control level and subsequently decrease the elevated brain content of $\mathrm{ACh}$ which detected in Pb-treated rats.

According to Sansar et al. (2012) the density of the immunoreactive serotoninergic cell bodies was significantly higher in $\mathrm{Pb}$ exposed rats in all parts of the dorsal raphe nucleus. Increases in synaptosomal serotonin level in cortex, cerebellum and hippocampus regions were also demonstrated by Chand et al. (2014). This is in agreement with our finding which declared that brains obtained from $\mathrm{Pb}$ exposed rats showed a significant elevation in 5-HT content when compared with control group. A possible explanation for our observations is that heme depletion caused by $\mathrm{Pb}$ exposure may result in inhibition of cytochrome P-450, which in turn results in inhibition of tryptophan pyrrolase, increased plasma tryptophan levels, elevations in brain serotonin levels, and, ultimately, aberrant neurotransmission of serotonergic pathways (Abadin and Liados, 1999). Brain of rats exposed to thiamine simultaneously with $\mathrm{Pb}$ showed a decline in the serotonin level when compared with $\mathrm{Pb}$ treated rats. This decrease in serotonin content toward control data may be responsible for the improvement in behavioral performance which detected in this group.

Our finding also revealed a significant decrease in the brain content of GABA, an inhibitory neurotransmitter which arises from astrocytic-derived glutamine. Adverse effect of $\mathrm{Pb}$ treatment on GABA was studied by Struzynska and Sulkowski, (2004) using synaptosomal fractions obtained from adult rat brain. They founded that both uptake and depolarization-evoked release of GABA were decreased by $40 \%$, relative to controls. Lower expression of GABA synthesizing enzyme and over 
expression of GABA transporter GAT-1 protein (possibly as a compensative mechanism) is also observed. Similar results were reported by Struzynska and Rafalowska, (1994). They demonstrated that $\mathrm{Pb}$ able to decrease of $\left[{ }^{14} \mathrm{C}\right]$ GABA content in synaptosomes of rat brain. In this study, we found that GABA content in brain homogenates of pbtreated rats declined significantly when compared with control group. Decreased GABA level may in apart the cause of excitation seen after acute $\mathrm{Pb}$ poisoning. Our results also showed a non-significant elevation in GABA content in group of rats treated with thiamine $+\mathrm{Pb}$ when compared with those exposed only to $\mathrm{Pb}$.

Moreover, a significant elevation in the levels of NE in brain of $\mathrm{Pb}$-treated rats was observed in the present study. This is in agreement with a number of previous studies which reported that $\mathrm{Pb}$ able to increase $\mathrm{NE}$ in different brain regions (Bijoor et al., 2012; Shailesh Kumar and Desiraju, 1990 and Chand et al., 2014). Authors demonstrated several mechanisms may be responsible for high levels of $\mathrm{NE}$ in different brain regions. Low levels of $\mathrm{Pb}$ caused release of $\mathrm{NE}$ from the secretory vesicles, by bringing about phosphorylation of proteins of the cytoskeleton, similar to what $\mathrm{Ca}^{++}$does. $\mathrm{Pb}$ also behaves as a chemical stress and stimulates tyrosine hydroxylase resulting in increased NE synthesis and release. Moreover, lead is believed to decrease the activity of mitochondrial monoamine oxidases (MAO) enzymes which resulted in decreased breakdown of NE. Moreover, Thiamine injection markedly decreased the level of $\mathrm{NE}$ in brain tissues of $\mathrm{Pb}$-treated rats when compared with animals received $\mathrm{Pb}$ only.

Histopathologically, the lesion of $\mathrm{Pb}$ toxicosis which was established previously in domestic animals consists of cortical cerebral necrosis with swelling of cerebral capillary endothelium. Cerebral edema, vascular congestion of meningeal vessels, and astrogliosis in the Purkinje and molecular layers of the cerebellum have also been reported (Jubb and Huxtable, 1993). The detected edema in the present study may be attributed to the increase in the permiability of the Blood Brain Barrier (BBB) leading to disturbances in the blood dynamics and escape of fluids to the nervous tissues and that agreed with previous studies which showed that the first step in the neurotoxic effects of $\mathrm{Pb}$ might be primarily related to damage to the permeability of BBB (Sun et al., 2008; Osterman et al., 2003). The microglial cells surround the degenerated neurons in a process called satellitosis and when the degenerated cells die the microglial cells will infiltrate the necrotic area and remove in a process called neurophagia and this was agreed with Johne and Hunt, (1983) and Ruan et al. (1996). Pathological lesions in brain and spinal cord of $\mathrm{Pb}$-exposed rats in the present study were with little degree of severity when compared with behavioral and biochemical alterations. This may be attributed to short term of $\mathrm{Pb}$ exposure and suggested that the neuro-toxicity of $\mathrm{Pb}$ mainly related to functional disturbances more than structural damage. Despite the less sever histological lesions which were detected in all $\mathrm{Pb}$-treated groups, the brain of rats injected with thiamine showed less degree of severity and incidence of such lesions.

In the light of the above, thiamine is extremely important vitamin for the brain, because it facilitates the use of glucose, thus ensuring the production of energy (Bourre, 2006). Our data showed that the coadministration of thiamine with $\mathrm{Pb}$ able to improve $\mathrm{Pb}$-induced memory and learning impairment with anxiety in rats, as indicated by comparatively better performance in MWM and EPM behavioral tests. A possible explanation for behavioral improvement is that thiamine able to alleviate $\mathrm{Pb}$-induced neurodamage by reversing its deleterious effect on neurotransmitter systems and neuro-morphology, as indicated biochemically and histopathologically. Moreover, protective effect of thiamine may be also attributed to that pyrimidine ring of this vitamin mediates its interaction with $\mathrm{Pb}$, leading to the prevention of its accumulation and/or increased clearance from tissues (Reddy et al., 2010). We suggested that the exact mechanism(s) by which thiamine can decrease $\mathrm{Pb}$ neurotoxicity need further future studies.

\section{CONCLUSION}

Behavioral alterations following $\mathrm{Pb}$ exposure have been linked to changes in neurotransmitters contents and histopathological lesions in the brain. Thiamine hydrochloride has a prophylactic potential against lead-induced neuro-toxicity which guided by marked improvement in behavior, neurotransmitters content and histological structure. We recommended the use of thiamine injection against cases suffered from subacute $\mathrm{Pb}$ poisoning.

\section{REFERENCES}

Abadin, H. and Liados, F. (1999): Toxicological profile for lead, Washington DC, Department of health and human services.

Bijoor, A.R.; Sudha, S. and Venkatesh, T. (2012): Neurochemical and neurobehavioral effects of low lead exposure on the developing brain. Ind. J. Clin. Biochem., 27: 147-151.

Bourre, J.M. (2006): Effects of nutrients (in food) on the structure and function of the nervous system: update on dietary requirements for brain. Part 1: micronutrients. The Journal of Nutrition, Health \& Aging, 10: 377- 385.

Chand, B.D.; Saya, R.N.; Usha, R.M. and Rajarami, R.G. (2014): Age related changes in aminergic system and behavior following lead exposure: 
protection with essential metal supplements. J. Neurosci Res.; 78: 81-89.

Culling, C.F. (1983): Handbook of histopathological and histochemical staining techniques, 3rd ed. London: Butterwort.

Goyer, R.A. and Clarkson, T.W. (2001): Toxic effects of metals, In Casarett and Doull's toxicology: the basic science of poisons, Sixth Edition, Edited by Klaassen, C.D.

Johne's, T.C. and Hunt, R.D. (1983): Veterinary pathology. Philadelphia.

Jubb, K.V.F. and Huxtable, C.R. (1993): Pathology of domestic animals, $4^{\text {th }}$ edition, San Diego, Academic Press.

Krametter-Froetscher, R.; Tataruch, F.; Hauser, S.; Leschnik, M.; Url, A. and Baumgartner, W. (2007): Toxic effects seen in a herd of beef cattle following exposure to ash residues contaminated by lead and mercury. The veterinary journal, 174: 99-105.

Kuhlmann, A.C.; McGlothan, J.L. and Guilarte, T.R. (1997): Developmental lead exposure causes spatial learning deficits in adult rats. Neuroscience letters, 233 (2-3): 101-104.

Kulkami, S.K. and Sharma, A.C. (1991): Elevated plus-maze: a novel psychobehavioral tool to measure anxiety in rodents. Methods Find Exp Clin Pharmacol., 13(8): 573-577.

Mansouri, M.T.; Naghizadeh, B.; Lopez-Larrubia, P. and Cauli, O. (2013): Behavioral deficits induced by lead exposure are accompanied by serotonergic and cholinergic alterations in the prefrontal cortex. Neurochem Int., 62(3): 232239.

Morris, R. (1984): Developments of a water-maze procedure for studying spatial learning in the rat. J. Neurosci Methods, 11: 47-60.

Mulder, G.B. and Pritchett, K. (2004): The elevated plus-maze. Contemp Top Lab Anim Sci., 43(2): 39-40.

Nava-Ruiz, C.; Mendez-Armenta, M. and Rios, C. (2012): Lead neurotoxicity: effects on brain nitric oxide synthase. J. Mol. Histol., 43(5): 553-563.

Osterman, H.; Ronen, C.; Hamos, J.; Miller, D.E.; Delgado, W. and Coulson, E. (2003): Safe Home Illinois. J. A Newsletter on childhood lead poisoning and prevention, PP. 6-7.

Phyu, M.P. and Tangpong, J. (2013): Protective effect of thunbergia laurifolia (Linn.) on lead induced acetylcholinesterase dysfunction and cognitive impairment in mice. Bio Med Research International, ID 186098, 6 pages.

Phyu, M.P. and Tangpong, J. (2014): Neuroprotective effects of xanthone derivative of Garcinia mangostana against lead-induced acetylcholinesterase dysfunction and cognitive impairment. Food Chem Toxicol., 70; 151156.

Radostits, O.M.; Gay, C.C.; Blood, D.C. and Hinchcliff, K.W. (2000): Veterinary medicine, a textbook of the diseases of cattle, sheep, pigs, goats and horses. Ninth Edition.

Reddy, S.Y.; Pullakhandam, R. and Dinesh Kumar, B. (2010): Thiamine reduce tissue lead levels in rats: mechanism of interaction. Biometals, 23(2): 247-253.

Ruan, S.Y., Gu, Z.W. and Ma, G.Y. (1996): Effects of lead acetate on the ultrastructural distribution of calcium and enzyme activities in rat brain cortex cells. J. Chin. Pharmacol Toxicol., 10: 294-297.

Sansar, W.; Bouyatas, M.M.; Ahboucha, S. and Gamrani, H. (2012): Effects of chronic lead intoxication on rat serotoninergic system and anxiety behavior. Acta Histochem., 114(1): 4145.

Senapati, S.K.; Dey, S.; Dwivedi, S.K.; Patra, R.C. and Swarup, D. (2000): Effect of thiamine hydrochloride on lead induced lipid peroxidation in rat liver and kidney. Vet. Hum Toxicol., 42(4): 236-237.

Shailesh Kumar, M.V. and Desiraju, T. (1990): Regional alterations of brain biogenic amines and GABA/glutamate levels in rats following chronic lead exposure during neonatal development. Arch Toxicol., 64(4): 305-314.

Sidhu, P. and Nehru, B. (2003): Relationship between lead-induced biochemical and behavioral changes with trace element concentrations in rat brain. Biol Trace Elem Res., 92(3): 245256.

Struzynska, L. and Rafalowska, U. (1994): The effect of lead on dopamine, GABA and histidine spontaneous and $\mathrm{KCl}$-dependent releases from rat brain synaptosomes. Acta Neurobiol. Exp., 54: 201-207.

Struzynska, L. and Sulkowski, G. (2004): Relationships between glutamine, glutamate, and GABA in nerve ending under pb-toxicity conditions. J. Inorg Biochem., 98(6): 951-958.

Sun, Y.; Sun, D.; Zhou, Z.; Zhu, G.; Lei, L.; Zhang, H.; Chang, X. and Jin, T. (2008): Estimation of benchmark dose for bone damage and renal dysfunction in a Chinese male population occupationally exposed to lead. J. Ann Occup Hyg., 52(6): 527-533.

Zhu, Z.; Yang, R.; Dong, G. and Zhao, Z. (2005): Study on the neurotoxic effects of low-level lead exposure in rats. $J$ Zhejiang Univ SCI., $6 \mathrm{~B}(7)$ : 686-692. 


\section{الثيامين عمل علي تحسين السمية العصبية للرصاص في فئران التجارب: تقييم طبائعي، وكيميائي وتركيبي أسامة سعبد العكل ، حسام جعفر تهامي ، راشد رجب راشد}

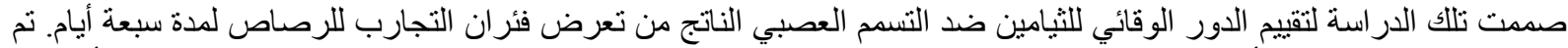

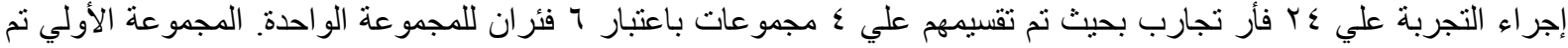

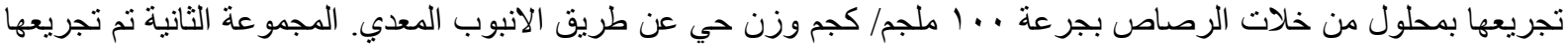

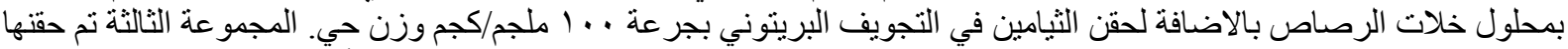

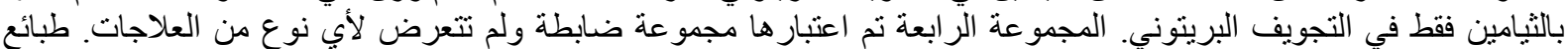

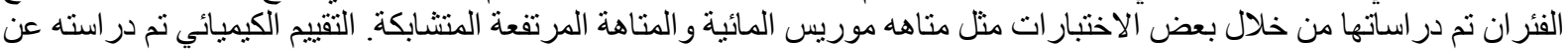

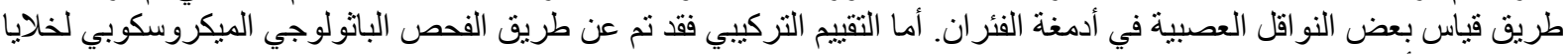

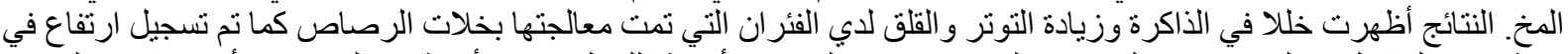

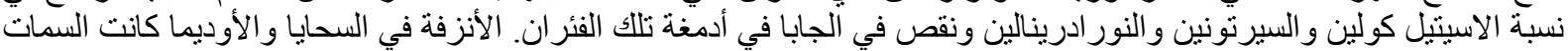

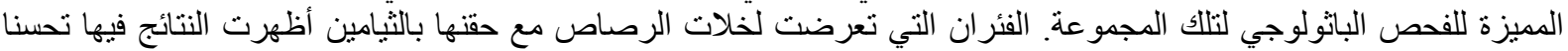

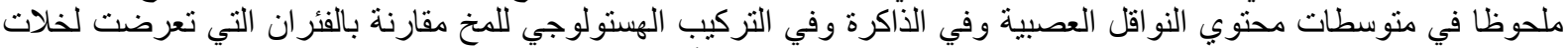

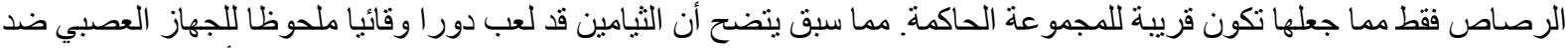

السمية العصبية للرصاص و بالتالي ينصح باستخدامة في الحالات تحت الحادة للتسمم بالرصاص و التئي ينجم عنها أعر اضا عصبية.

الكلمات الدالة: رصاص، سمية عصبية، نو اقل عصبية، باثولوجي، ثيامين. 